\title{
Corposições entre o ver, o dizer e o agir
}

\author{
Catarina Mendes Resende, Iacã Machado Macerata ${ }^{I}$ Leticia Costa Barbosa, ${ }^{I I}$ Mariana Barbosa Pimentel, III \\ Mariana Borges de Moraes, ${ }^{I}$ Cesar Augusto de Macedo, ${ }^{\text {IV }}$ \\ ${ }^{I}$ Universidade Federal Fluminense, Niterói, RJ, Brasil /II Fundação Oswaldo Cruz, Rio de Janeiro, RJ, Brasil \\ ${ }^{I I I}$ Universidade Nova de Lisboa, Lisboa, Portugal / ${ }^{I V}$ Universidade Federal do Rio de Janeiro, Rio de Janeiro, RJ, Brasil
}

\section{Resumo}

Este artigo enuncia as questões que mobilizam o coletivo de investigação "Corposições: Profanações entre afeto, performatividade e território", explicitando o "como", "onde" e "quando" os campos de atuação de seus integrantes se imbricam para construir um corpo comum. A partir de suas principais ferramentas de trabalho - a Composição em Tempo Real de João Fiadeiro e o Modo Operativo AND de Fernanda Eugenio - o jogo proposto pelo grupo é o de partilhar suas experiências, dando visibilidade ao que desestabiliza, ventila e amplia suas práticas e discursos. Tal proposição implica modos de ver especificos - a articulação entre corporeidade, afeto, território e performatividade - e modos de agir - uma investigação que é experimentação e laboratório, na qual são performadas intervenções entre dança e clínica.

Palavras-chave: Composição em Tempo Real; Modo Operativo AND; corporeidade; dança; clínica.

\section{Corposições between seeing, saying and acting}

\begin{abstract}
This article states the questions that mobilize the research group "Corposições: Profanations between affection, performativity and territory". It highlights "how", "where" and "when" the fields of action of its members imbricate to build up a common body. Considering its main work tools - João Fiadeiro's Real Time Composition and Fernanda Eugenio's AND Operative Mode - the game proposed by the group is to share their experiences, giving visibility to what destabilizes, ventilates and broadens its practices and discourses. This proposition implies specific ways of seeing - the articulation between corporeity, affection, territory and performativity - and ways of acting - an investigation which is experimentation and laboratory where interventions between dance and clinic are performed.
\end{abstract}

Keywords: Real Time Composition; AND Operative Mode; corporeity; dance; clinic.

\section{1- Panorama}

Este artigo enseja apresentar o coletivo de investigação "Corposições: Profanações entre afeto, performatividade e território", que investiga e propõe composições entre arte e clínica. Mais do que apresentar nosso coletivo, interessa-nos "mostrar" como, onde/quando as questões dos vários componentes se imbricam, formando assim, um corpo comum do grupo. Corpo comum que por sua vez é repartido em cada prática que se realiza fora do Corposições. Trata-se aqui de um duplo exercício: apresentar e enunciar trajetórias específicas que se encontram, que constróem uma superfície de contato; indicar as consequências - que não deixam de ser causas - que esta superfície produz nos âmbitos que cada componente atua. Um movimento constante de encontro-dispersão-reencontro constitui nosso "jogo": " uma experiência coletiva, e sempre parcial e provisória, de enunciar o indizível que nos une.

Aqui falamos de trajetórias ou corpos muito diferentes que, em uma primeira mirada, poderiam ser divididos em dois grandes campos: a dança e a clínica. Porém, ao nos determos mais atentamente, vemos não se tratar Da

\footnotetext{
^Endereço para correspondência: Universidade Federal Fluminense, Departamento de Psicologia Rio das Ostras. Rua Recife - até 599/600 - Jardim Bela Vista. Rio das Ostras, RJ - Brasil. CEP: 28895532.E-mail: catarinamresende@ gmail.com, imacerata17@gmail.com, letibarbosa@gmail.com, maribpimentel@gmail.com,marianabmoraes@yahoo.com.br, artegutal@gmail.com

${ }^{1} \mathrm{O}$ modo como compreendemos esse jogo da nossa escrita nos aproxima da noção de "dispositivo", uma vez que nosso primeiro exercício é darmos relevo às curvas de visibilidade e de enunciação num conjunto multilinear e heterogêneo que opera em devir. Nas idas e vindas entre o ver e o dizer, nossso jogo vai pondo em relevo também as linhas de ruptura, de subjetivação e de força que o compõem entre a desestabilização e a consistência (DELEUZE, 1996).
}

Dança, Da Clínica. O que aqui se compõe é feito de várias práticas e persespectivas que atravessam a dança e a clínica. Temos ao mesmo tempo alguns pontos comuns e alguns pontos de particularidades irredutíveis. Isso requer - e se trata de um aviso - uma estratégia narrativa que ora fala em um nós, ora em um ele/ela, ora em um eu. Cada pronome pessoal nada mais é que um agenciamento coletivo de enunciação (DELEUZE; PARNET, 1998) momentâneo de processos irredutíveis ao nome que se dá. Nosso problema é esse e sempre retorna: a enunciação. Com esse problema nos ocupamos sem nenhuma intensão de esgotá-lo: trata-se mesmo de mantermo-nos neste jogo/exercício de expressar o mesmo problema de modos diferentes. De modo que o problema nunca é "um já aí", e tampouco um lugar a se chegar de vez por todas. Nosso jogo de dizer é fazer ver as relações que compõem nossas problemáticas, recriando-as: ato performativo de enunciar com aquilo que fissura e escapa do já dito.

Enunciar (com) um coletivo que ganha corpo passa inevitavelmente por localizar um encontro que teve efeito (afetivo) de enunciação: o encontro com Modo Operativo AND (MO_AND), desenvolvido pela antropóloga brasileira Fernanda Eugenio, em articulação com a Composição em Tempo Real (CTR) desenvolvida pelo coreógrafo português João Fiadeiro. ${ }^{2}$ Encontro Brasil-Portugal, encontro de placas tectônicas que reverbera blocos de encontros-acidentes. $\mathrm{O}$ encontro de cada um de nós com o MO_AND e com a CTR produziu um efeito enunciativo,

${ }^{2}$ Tais ferramentas serão apresentadas quando estivermos descrevendo o mapa das condições iniciais de nosso jogo na sessão 2 . 
não de decifração, mas de "sacação": "Ah! então é isso!”. Sensação-sentido partilhado de um fazer ver e fazer falar algo que cada um a seu modo vinha perseguindo, em sua trajetória específica. O MO_AND e a CTR foram para nós a expressão presentificada de visões de mundo, de modos de ver, que partilhávamos, que se articulavam e se concretizavam ou corporificavam em um dispositivo de jogo. Dizemos que o encontro "deu onda": mergulho do corpo e do pensamento em uma trama molecular ${ }^{3}$ das substâncias que os compõem. No MO_AND iam se implicando e se articulando pessoas com práticas as mais diferentes.

$\mathrm{O}$ interesse e o envolvimento comum com o $\mathrm{MO}_{-}$ AND fez com que nos juntássemos primeiramente para estudar e praticar o dispositivo jogo, e posteriormente para investigar não somente o MO_AND, mas através deste. O MO_AND é uma perspectiva e um dispositivo que compôs com nossa perspectiva e outros dispositivos de que já dispúnhamos, veiculando o desdobramento de um processo de investigação. Por perspectiva entendemos um modo de ver e um modo de agir situado em um corpo, seja ele individual, seja coletivo. Um corpo-perspectiva entendemos como uma localização, uma articulação em um espaço-tempo que agencia, apreende e expressa um modo de ver o mundo, também um modo de agir, de construir o que se vê. Corpo-perspectiva como um modo de ver é uma operação de "ver como..." (MACERATA, 2015). A instância que concretiza uma perspectiva é o corpo, ao mesmo tempo que o corpo determina a perspectiva (CASTRO, 1996, 2010).

Se cada um de nós foi tendo seu modo de ver e agir em sua prática modificado pelo encontro com o MO_AND e com a CTR, ao mesmo tempo nos interessava continuar jogando, tirando consequências disso, continuar atualizando isso que fez efeito, essa sacação, essa onda. Mas a onda e a sacação individual - que se deram como efeito no pensamento e no corpo - também se davam pelo encontro entre nós. Nosso processo de investigação portanto trata de estabelecer certa zona de interesse comum, construindo alguns dispositivos para nos ocuparmos desse comum, e que acaba por (re)definir cada prática individual fora do espaço do coletivo.

Neste artigo propomos um jogo que é o de enunciar o que experienciamos em rede, dando visibilidade ao que desestabiliza, ventila e amplia nossas práticas e discursos. Aqui nos interessa apresentar o nosso coletivo como uma composição que nos faz compartilhar um corpo comum, mas que também nos convoca a tomar posição com/em nossos corpos na relação com os outros: nossas práticas na clínica e na dança fora do corposições. Estamos enunciando o comum do grupo a partir da articulação entre três "motivos"/temas que entendemos estarem mutuamente implicados: afeto, performatividade e território. Tal comum, podemos dizer, se apresenta também em nossas práticas individuais e compõe uma corporeidade coletiva. Nossa investigação se faz como

Molecular aqui se refere a uma dimensão da realidade ali onde a realidade é an-
terior às formas molares, nomeáveis, delimitadas, dizendo respeito aos processos
que tem consistência das forças, afetos. Realidades pré-conscientes, pré-indivi-
duais, dimensão pré-individuada. O conceito dupla face molar/molecular está em (DELEUZE; GUATTARI, 1997). experimentação que gira em torno do tabuleiro de jogo do AND, ou do espaço demarcado da performance da CTR, mas que tende a trazer para nossa experiência outros usos desses dispositivos e dessas duas perspectivas. Aquilo que entendemos por profanar: se por um lado o encontro com tais persepctivas e dispositivos profanou nossa própria prática individual, nosso coletivo trabalha no sentido de utilizar o MO_AND e a CTR para produzir outros espaços de experimentação, profanando-os. Essa é a direção e o modo de proceder que queremos afirmar. E este artigo tem a função de demonstrar tal horizonte e tal caminhando. Ao fim e ao cabo, de nossa experiência nas ferramentas, do nosso espaço coletivo e das nossas práticas fora do grupo, temos como efeito a emergência disso que chamamos corposições.

\section{2-Mapa das condições iniciais de nosso jogo}

\section{1-As ferramentas-perspectivas catalisadoras: a CTR e o MO_AND}

Duas são as ferramentas principais no âmbito de nossa investigação e constituição como grupo de estudos: a Composição em Tempo Real (CTR) desenvolvida pelo coreógrafo português João Fiadeiro desde 1995 e o Modo Operativo AND (MO_AND), criado pela antropóloga brasileira Fernanda Eugenio em interlocução com João Fiadeiro entre os anos de 2011 e 2014, enquanto juntos co-dirigiram o AND LAB - Centro de Investigação Artística e Criatividade Científica.

Antes de mais nada, é preciso remarcar um duplo sentido do que estamos chamando de ferramenta. Aqui ferramenta é tanto um dispositivo prático, que se concretiza em um instrumento com um certo método - um jogo, no caso do MO_AND - mas também fala de uma prática teórica, ou ainda, para nós, uma perspectiva, um modo de ver a realidade, que implica posicionamentos perceptivos, éticos, estéticos e políticos. De modo que se temos uma ferramenta concreta, como instrumento que pode ser usado, que se repete, digamos um certo corpo, temos também uma perspectiva, como posicionamento num espaço de relações muito amplo: um modo de ver no mundo. Toda concreção, corpo, veicula e é veiculada por um olhar, um modo de ver e de agir.

É nesse sentido que João Fiadeiro, em seu dossiê sobre a CTR, a define como "uma ferramenta teórico-prática que estuda, problematiza e sistematiza a experiência de improvisação e da composição em arte, utilizando o campo proporcionado pela dança contemporânea como território privilegiado de investigação e aplicação" (FIADEIRO, 2016, p. 2). Neste método, o ato criador precisa ser resultado de um encontro, e não exatamente da mente Do Artista. Não resulta de uma projeção pessoal, seja ela explícita ou implícita. A partir do encontro com um tempo, um espaço, um outro, uma coisa, um afeto que serão geradas as condições de descoberta daquilo que de fato toca, move e infeta o coletivo, que constrói então a partir da suspensão das trajetórias individuais seu plano comum de partilha. A prática da CTR desenvolve-se em estúdio a partir de um simples dispositivo: um claro enquadramento espacial (um dentro e um fora) e temporal (um antes e um depois). No início, os participantes encontram-se 
"fora" do espaço delimitado e o trabalho começa no momento em que a atenção dos participantes se concentra no espaço "em branco", o que já constitui uma pré-ação. São necessários certos acordos e princípios prévios para que se desenvolva a ética do comum e da suficiência, aspectos vitais deste método, os quais também podem ser chamados de "sensibilidade às condições iniciais": a capacidade de inibir o reflexo - tendo em vista que a ação por impulso revela a necessidade pessoal do participante de ter uma ideia e apresentá-la aos demais; o agir em silêncio, sem explicações ou justificativas; a capacidade de concretizar relações entre posições (e não entre situações, como tendemos a operar) e a restrição de não se poder fazer duas jogadas seguidas. A dinâmica do método acontece de forma circular e cumulativa, num movimento constante entre o que está "fora" e o que está "dentro", movimento este que pode ser interrompido por feedbacks meticulosos os quais constituem uma ferramenta central no processo de transmissão do mesmo. A CTR antes desenhada como suporte de pesquisa coreográfica das criações de João Fiadeiro afirma-se, após o encontro com Fernanda Eugenio e a contaminação pelo MO_AND, também como instrumento e plataforma teórico-prática para pensar a decisão, a representação e a colaboração.

Desdobrada, pensada e praticada como investigação, prática de formação e prática de jogo, o MO_AND é uma "abordagem ético-estética de aplicabilidade transversal, dedicada à 'pensação' dos funcionamentos e modulações do acontecimento e à mediação das relações" (EUGENIO, [201?], online), que vem sendo desenvolvida pela antropóloga Fernanda Eugenio. Emergiu da contaminação recíproca entre o método da Composição em Tempo Real (João Fiadeiro) e o método da Etnografia Aplicada à Performance Situada desenvolvida por Fernanda Eugenio. Pode-se definir o MO_AND como "um sistema de ferramentas-conceito e conceitos-ferramenta de aplicabilidade transversal à arte, à ciência e ao cotidiano para a tomada de decisão, a gestão sustentável de relações e a criação de artefactos" (EUGENIO; FIADEIRO, 2013, p. 222). Guiado pelas perguntas “como viver juntos?" e “como não ter uma ideia?", o MO_AND se utiliza de um dispositivo-jogo que permite praticar tal modo de operar, ao mesmo tempo que constrói um corpo teórico.

O jogo se dá da seguinte forma: no plano laboratorial estabelece-se um espaço inicial com a demarcação de um quadrado no chão com fita adesiva, que produz um acordo comum de fronteira fictícia entre os espaços dentro e fora do quadrado. O quadrado, também chamado de tabuleiro, cria uma zona de atenção compartilhada e de jogo. Cada inserção/subtração neste quadrado é uma jogada, chamada de tomada de posição. Cada tomada de posição é uma modificação da paisagem do tabuleiro. Há geralmente um número de objetos que podem ser manuseados pelos participantes em suas tomadas de posição, podendo o corpo também estar implicado nas jogadas/posições. É um jogo cujas regras são encontradas no próprio jogar. O jogo do jogo é "encontrar o jogo", entendido como o exercício da construção do plano comum. Encontrar o jogo exige ao menos três tomadas de posição: a primeira jogada instaura a posição 1. A segunda, uma segunda posição que cria uma primeira relação. A terceira posição/ jogada poderá criar uma relação com a relação anteriormente presente. A primeira jogada é a mais aberta, na qual todos os hologramas são possíveis; a segunda pode clarificar o afeto em jogo, enquanto a terceira pode confirmar o afeto comum e assim possibilitar que o grupo "encontre o jogo". O exercício de escuta e do reparar norteiam as ações que se sucederão, de acordo com o que o acontecimento pedir. Assim, uma posição é a perspectiva de um corpo situado, considerado na sua relacionabilidade; é o gesto de afirmar uma localização e uma duração num espaço-tempo circunscrito, tomar parte e partilhar, no mesmo movimento, as linhas de visibilidade e dizibilidade de um plano comum. Cada posição será sempre tomada na sua dimensão composicional, no ato de criar materialidade às relações que estão em relação.

O MO_AND foca no afeto e suas relações, em um espaço "entre", refletindo sobre a gestão de uma comunidade que não hierarquiza sujeito, objeto e acontecimento, retardando o mecanismo do "saber" em prol da emergência do "sabor" (EUGENIO; FIADEIRO, 2013). O protagonismo do sujeito transfere-se para o do acontecimento. Essa transferência dá-se substituindo as perguntas habituais do sujeito - quem e por quê? - por interrogações que o acontecimento nos coloca: o quê, como, onde e quando? Pergunta a cada situação que se apresenta: $\mathrm{O}$ quê, aí está? Como, neste quê? Onde e quando, com este como? Um laboratório de hipervisualização do plano molecular dos encontros.

Podemos entender o MO_AND como um modo de ver e agir, uma perspectiva, que veicula um corpo teórico e prático de exercícios que podem se dar no espaço do dispositivo do jogo, mas que também pode (e se dá) em qualquer espaço de vida. O MO_AND tando quanto a CTR podem ser enunciados também como exercícios no modo de compor: de modo que qualquer composição seja guiada e sustentada não em um líder ou em uma ideia, mas no acontecimento tal como ele se dá em um território que envolva os mais variados agentes. Atualmente, o MO_AND concentra-se na abordagem ético-estética dos usos políticos da etnografia nos mais diversos meios de atuação, enquanto a CTR retorna seu foco para a composição em arte, nomeadamente, em dança e suas interfaces com outras áreas.

\section{2-As posições iniciais em nosso coletivo: posição com-posição}

Neste ponto, entramos no exercício de narrar nosso "tabuleiro" do Corposições. São as paisagens de um encontro que se corporificam a partir de vários encontros em tempos distintos e que têm como porta de entrada o $\mathrm{MO}_{-}$ AND e a CTR. Entramos em relação com um corpo situado e afetado por estes paradigmas-ferramentas e narramos menos as nossas histórias e mais o que carregamos em nós, como se dão nossos deslocamentos durante a criação de superfícies de contato entre os integrantes do Corposições. Trata-se de um exercício de apresentar as "posições 1" que cada um trouxe ao grupo, e que geram nossas 
com-posições; revelando nossa sensibilidade às condições iniciais de relação (pondo em cena uma espécie de começo que não pretende estabelecer uma origem). Para tanto, fizemos uma rodada de entrevistas com cada integrante, buscando construir uma linha temporal do nosso primeiro encontro com as ferramentas, mas também como esse encontro tem se propagado em nós, dialogando ou produzindo questões para/com nossas práticas. As entrevistas gravadas em áudio, foram transcritas, e aqui fazem uma aposta narrativa: o escrito que se segue mantém a voz de seu narrador, que em algum momento passa a ser outra, e depois outra, até traçarmos todos os nossos modos de entrar em relação mútua. $\mathrm{O}$ objetivo é dar a ver uma corporeidade coletiva emergente, por movimentos que se entrecruzam, vão-e-voltam no tempo, entram numa espiral de começos e recomeços, recuam para avançar, se ensinuam entre o individual e o coletivo, entre o eu e um qualquer. Movimentos de ligação, movimentos que nos distiguem, mas não nos separam em nossas corposições.

O primeiro contato com a CTR aconteceu no Atelier RE.AL em Lisboa no ano de 2008, período em que as minhas criações se situavam num plano demasiado representativo. Cada movimento surgia como explicação e mimesis de uma ideia prévia e isso me incomodava profundamente. Outro aspecto é que minha criação individual nunca envolveu a invenção de frases coreográficas extremamente definidas e marcadas. Dependendo da maneira como são organizadas, as frases coreográficas encerram-se em uma virtuose que pouco tem a acrescentar à percepção. ${ }^{4} \mathrm{~A}$ prática da CTR é, portanto, para mim, conseguir lidar radicalmente com essas inquietações.

$\mathrm{O}$ meu afeto e interesse neste trabalho estão intimamente ligados a habitar o vazio e dele fazer emergir algo. Como fazer emergir um espetáculo a partir de um simples objeto ou ação? A sensibilidade às condições iniciais, o trabalhar com o que se tem, o esmiuçar profundo de um objeto indo além de sua função, assim como uma ação contém muito mais do que o que está na superfície do fazer; e a inibição do reflexo que vem carregado de tais ideias prévias são aspectos inerentes deste método que me mobilizam e alteram minha forma de enxergar a criação.

A articulação deste método com o MO_AND colocou em relevo outros aspectos importantes no meu processo perceptivo tais como o foco na relação entre o que está no espaço e a dimensão de jogo nesta interação com o outro - um outro que está dentro e está fora, trazendo a questão: existe de fato esta diferenciação? Outro componente foi a extrapolação do espaço do estúdio para o espaço urbano, o que trouxe práticas etnográficas fundamentais para pensar processo criativo na dimensão arte-vida.

Estas perspectivas influenciam intensamente o meu fazer, que consiste na criação e apresentação de espetáculos de dança contemporânea, na gestão e produção cultural, na curadoria, na formação artística por meio da proposição de oficinas, na escrita e produção teórica. $\mathrm{O}$ que antes parecia pura plataforma de apresentação de

\footnotetext{
${ }^{4}$ Neste escopo, a identificação com métodos de criação heterodoxos - como de Merce Cunningham, por exemplo -, foi crescendo bem como com metodologias que criassem um ambiente de co-responsabilização e horizontalidade entre os materiais.
}

uma ideia, agora torna-se plataforma de encontro e compartilhamento de uma comunicação fina do corpo sutil. Este pensamento faz relativizar a angústia presente em um processo criativo nos momentos de crise, pois possibilita a observação da cena e seus componentes com certo distanciamento necessário para quem cria, dirige e atua simultaneamente - fato tão presente nesta contemporaneidade recheada de artistas-etc. ${ }^{5}$ Faz desconstruir as próprias expectativas, fazendo com que o processo seja ainda mais desafiador porque despido de saberes prévios e execuções puras de ideias as quais muitas vezes estão mais relacionadas ao "ego" do que ao comprometimento do que se está trabalhando no espetáculo - sobretudo para artistas da dança que passam grande parte de sua formação observando-se no espelho.

Outro importante mote neste processo é a construção de um plano comum de leitura da imagem-cena, o que não significa uma leitura igual para todos e decifrável por meio de explicações e interpretações fechadas, verticais e hierárquicas. O desenvolvimento do plano comum é aguçar as percepções, o parar e o re-parar na transversalidade das relações: o público não é um mero receptor. Ele constrói junto com o que está em cena o que ela se propõe. Público e artistas são co-criadores do acontecimento. ${ }^{6}$ Tal co-responsabilização mobiliza a criação para um lugar de partilha colaborativa desde o início do processo até a apresentação do espetáculo, já carregado de alteridade.

Depois de uma longa trajetória com o Grupo Coringa (RUIZ, 2013), e nos últimos anos, em crise com o Contato Improvisação - CI (KALTENBRUNNER, 1998), conheço a abordagem psicossomática Movimento Autêntico - MA (JORGE, s.d., online), através da professora Soraya Jorge ${ }^{7}$ que estava introduzindo esse trabalho no Rio de Janeiro/Brasil. Inicio um mergulho prático com ela na pergunta pilar desse sistema: "O que me move?", “O que me faz mover?", e decorre um resgate do prazer de improvisar com o CI. Assim, dadas as condições, iniciamos uma parceria de pesquisa sobre como funcionar juntando o CI com o Contato Autentico (KALTENBRUNNER, 2009). Fizemos algumas propostas durante o nosso percurso, usando o Contato Autêntico como processo de criação, convidando um público para assistir uma performance, criando a Jam-Roda Viva (MACEDO, 2007)... e foi nesse momento que conheci o João Fiadeiro com a CTR.

Depois de muito tempo fazendo as Jams-Roda Viva, oferecendo algumas performances junto com um grupo de estudos, reapareceu a Fernanda Eugenio (que já tinha feito com a Soraya o Movimento Autêntico) junto com o João Fiadeiro, apresentando um jogo, o MO_AND. Eu me deparei muito com as minhas limitações... estou falando do "ego", né?... das tomadas de decisão... e do desejo de criar algo já pré-definido... então foi importante

${ }^{5}$ Conceito desenvolvido pelo artista e professor Ricardo Basbaum (2005), que evidencia um aspecto característico do artista contemporâneo que possui diversas outras funções para além do criar e apresentar.

${ }^{6}$ Indico aqui a bibliografia do autor contemporâneo Jacques Rancière, tais como $A$ partilha do sensivel (2005) e $O$ espectador emancipado (2010).

${ }^{7}$ Soraya Jorge, embora esteja afastada durante os anos de 2016 e 2017, também faz parte do coletivo Corposições. 
aprender a parar e re-parar, entender o movimento coletivo... e como isso poderia ser transformador da própria forma de criar. Poder criar com mais cooperação e não só com uma parceria única. Tenho uma sensação de que coisas que eu fiz há 30 anos atrás... agora estou me apropriando, podendo oferecer. Mover a partir da sensação do corpo. O MO_AND foi algo que me impulsionou pra um lugar que eu não sabia como ir, mas desejava! Porém, ao enunciar, aquilo já se... já se... neutralizava! Então isso foi quase que uma mágica, fazer o quadrado... e aquele vazio se estabelece, aquela atenção se estabelece... e eu não tenho que falar mais nada! Eu fiquei muito angustiado com isso, como o meu eu aparece nos nossos jogos. O nosso grupo foi muito terapêutico pra mim; aprender a parar, a reparar, a encontrar outro tempo, produzir o tempo coletivamente foi um grande ganho.

Por uma série de co-incidências fui sendo levada à João Fiadeiro, à Fernanda Egénio, ao Atelier RE.AL, onde me hospedei por 4 meses durante o meu doutorado-sanduíche, em 2012. É assim que chego ao MO_AND: pela SECALHARIDADE. ${ }^{8}$ É este o meu primeiro afeto-impacto: alimentar a visibilidade de linhas que se compõem na errância e ganham a vibratilidade de um acontecimento. Acolher e lidar com aquilo que calhou em por-se lado a lado.

Chego ao MO_AND pelos encontros entre brasileiros e portugueses. Chego ao MO_AND pelos desencontros entre o português e o "brasileiro". Neste caso me refiro à experiência de ser estrangeira na língua materna: uma experiência limite de dilatação da sensibilidade às rupturas que se dão na continuidade de um mesmo mundo comum - ser estrangeira à própria enunciação.

Lembro da aposta do Eduardo Passos: "você precisa conhecer o coreógrafo João Fiadeiro em Lisboa; o que eu vi do trabalho dele em Fortaleza é muito clínico!"; e uma vez ali, vejo as possibilidades de um mergulho na aproximação com a clínica. Uma clínica que emerge de uma certa secalharidade; no sentido que se direciona menos por um projeto psicoterapêutico e mais por uma atitude ética composta pelos encontros; se sustenta não num sólido pilar verticalizado pelo saber-poder de um especialismo, mas sim numa superfície trepidante criada a partir de um fora, operando por intercessores (DELEUZE, 1992): por atravessamentos e ressonâncias entre elementos heteróclitos com a potência de conectividade e de produção de sentido. Uma clínica que tem no desenvolvimento do vínculo terapêutico a confiança de um acompanhamento mútuo, e nessa trajetória compartilhada, uma aposta na produção (e acolhimento) de desvios que favoreçam a diferenciação e a consistência de um plano comum (num "tipo" de sensação de pertencimento naquilo que se compõe com a diferença, de se sentir continuando-a-ser-o-mesmo com tudo que se tornou estranho).

\footnotetext{
${ }^{8}$ Neologismo de Fiadeiro e Eugenio para uma lógica do acontecimento, a partir de uma expressão muito usada em Portugal: "se calhar". Há um siginificado mai ampliado daquele que teríamos aqui no Brasil, pois muitas vezes é empregado no sentido paradoxal de indicar a possibilidade de algo acontecer, já acontecendo. Há uma espécie de contração do tempo em que aquilo que irá acontecer já está acontecendo: "se calhar, te deixo aqui nessa esquina", disse uma amiga que me dava uma carona, já parando o carro.
}

O MO_AND me emprestava um tabuleiro onde toda essa dinâmica podia ser "jogada" a partir de microacontecimentos que passavam a ter estatuto de existência. Era como encontrar um laboratório de hipervisualização do plano molecular dos encontros, e consequentemente, o que isso mobiliza na escala dos afetos (RESENDE, 2012). Uma espécie de maquete das sutilezas.

Já de volta ao ato de clinicar, o MO_AND me sensibiliza às condições iniciais de um primeiro encontro (uma entrevista, por exemplo), às múltiplas dinâmicas que estão se compondo pelo entrecruzamento de linhas errantes que favoreçam a vibratilidade de um acontecimento, uma primeira conexão em que nos sentimos criando uma língua comum para o indizível dos afetos. Uma sensibilidade às condições iniciais da sintonia dos corpos na clínica.

$\mathrm{O}$ encontro é uma ferida. Uma ferida que, de uma maneira tão delicada quanto brutal, alarga o possível e o pensável, sinalizando outros mundos e outros modos para se viver juntos, ao mesmo tempo que subtrai passado e futuro com a sua emergência disruptiva (EUGENIO; FIADEIRO, 2012, s/p.).

Este é um trecho do texto "O encontro é uma ferida" (EUGENIO; FIADEIRO, 2012). E é com este texto que acontece meu primeiro encontro com o que vou descobrir em seguida ser o MO_AND. Neste momento da história do MO_AND a conversa com a psicologia clínica já tinha começado, estava em estado de reconhecimento. Percebíamos suas coincidências, usávamos esse novo olhar para ativar nossos próprios conceitos. Um segundo encontro, que de certo modo é o primeiro, se dá no workshop ministrado por João e Fernanda na Unirio, em 2013.

O que eu lá (vi)via era a experiência de manuseamento pelo próprio clínico dos afetos que dão direção aos diversos elementos que surgem no setting. Elementos, por exemplo, como o tempo de uma intervenção, a verificação da justeza dessa intervenção e também a abertura dela para que possa ganhar a força de um acontecimento. Além do improviso, que nos campos científicos tem caráter tão pejorativo, mas que faz parte de nosso cotidiano e que neste jogo é o foco, digo mais, é a ciência.

Esse efeito foi experimentado por mim e por meus pacientes imediatamente. Todos os dias ao fim do workshop eu retornava à minha prática clínica e punha essa nova sensibilidade para jogo. A ferida estava ali aberta e meu possível e meu pensável já tinham outras dimensões. Essa diferença foi percebida e sinalizada por muitos dos pacientes que puderam dizer coisas como: “O que está acontecendo? Tem algo diferente aqui e não consigo ver o que é!". Essa percepção era física! Era material! O MO_AND e a minha clínica entraram em relação.

Ali eu vivi o pensamento em meu corpo, tinha forma, contorno, era palpável, às vezes mais rígido, às vezes mais maleável. Todo o tempo em que venho estudando, praticando e transmitindo o MO_AND, a experiência da concretude dos afetos e do pensamento sempre me soou como primordial. Tão primordial, que o próprio jogo do MO AND para se iniciar, primeiro precisa desarticular as ferramentas que fazem com que o pensamento se destaque de sua dimensão material. Busco então fazer consis- 
tir. E o faço apronfundando numa pesquisa de mestrado que busca pensar as articulações possíveis entre a clínica e o MO_AND. Essa pesquisa se apresenta como uma pesquisa de meu próprio corpo, de meu corpo clínico. Uma pesquisa talvez em equivalência com os exercícios de propriocepção, que permitem reconhecer seu corpo, suas possibilidades, seu tônus.

Como entender o outro como um sujeito inteiro, não fragmentando e cindido quando no momento histórico atual, o corpo é objetificado, domesticado e anestesiado o tempo todo? Quais são as possibilidades na clínica em operar sobre este sujeito que pede ajuda escapando a esta leitura de mente e corpo como partes distintas de um todo? Como criar um espaço no encontro clínico para que o outro seja visto e se perceba para além da lógica da representação? Como produzir novos sentidos através dos afetos vividos no encontro, e não reduzir a intervenção clínica à elaboração discursiva do sofrimento?

Estas perguntas foram suscitadas em meio a muitas angústias vividas durante a prática clínica, não somente a angústia trazida pelos pacientes, mas as sensações emergentes em meu corpo durante e após os atendimentos. Em muitos casos, o sentimento que eu experimentava era ao mesmo tempo de uma grande dificuldade em intervir no sofrimento do outro e uma impossibilidade de elaborar o encontro em meu corpo. $\mathrm{O}$ ingresso na pós-graduação lato sensu em Terapia pelo Movimento - Corpo e Subjetivação, e os contatos com o Movimento Autêntico e a ferramenta MO_AND foram grandes marcos nesse processo, em que pude reinaugurar um campo sensível fundamental para minha clínica. Com os encontros do nosso grupo, veio a vontade de experimentar a ferramenta na clínica. Apresentava o jogo para alguns pacientes, quando queria experimentar uma outra forma de estar junto, de produzir uma forma de conversar que abdicasse da fala, sobretudo em casos em que não conseguia me sentir em uma sintonia fina com o paciente a partir de sua fala e de minhas pontuações.

Propus, então, o jogo a um paciente de 12 anos. Tínhamos feito algumas sessões, e percebia que até ali nossa conversa se limitava às minhas proposições de algumas atividades e a ele, a execução. Pouco conversávamos e nenhum interesse por parte dele sobre as atividades propostas e sobre a possibilidade dele propor apareceram até então. Sentia que precisava estar junto de outra forma. A partir de nosso primeiro jogo, passei a construir com ele um jogar nosso, e prontamente nossas posições no encontro clínico mudaram. Deixei de ser propositora e passei a jogar junto. Ele demonstrou um grande interesse pelo jogar, e passou a propor o jogo por muitas sessões consecutivas. E o que me chamava a atenção era não somente o quanto ele estava interessado naquilo que fazíamos juntos, mas também as sensações que percebia em mim a cada sessão. Uma euforia, agitação, um pensar com o corpo inteiro.

E a partir dessa experimentação conjunta, trouxe a ferramenta para a clínica de forma mais frequente. E para cada paciente que propunha, uma experiência de jogar inteiramente diferente. Passei a reparar no que eu sentia durante o jogo, a cada tomada de posição, nas sen- sações que emergiam de cada encontro. Saía do lugar de simplesmente compreender a fala do paciente, e me colocava na posição de viver uma fala construída conjuntamente, num execício coletivo de enunciação. E o jogar propiciava perceber o afeto conjunto, que composições afetivas emergiam pelo encontro. Era possível perceber como o outro me afetava e devolver o afeto com outra modulação, numa experiência de sintonia. O uso do jogo trazia uma espécie de amplificação da minha percepção do campo afetivo, abrindo meu corpo para perceber os gestos que até então não eram possíveis perceber.

Evidenciava-se mais ainda que ignorar a corporeida$\mathrm{de}^{9}$ na clínica é não considerar as propriedades do corpo como produtor de sentidos. Participar desse coletivo permitiu-me pensar uma clínica sensível como jogo-acontecimento, a perceber a construção conjunta da comunicação e do afeto, do entre.

O que me chamou para o MO_AND foi o olhar e o agir em relação ao tabuleiro: no tabuleiro antes de sujeitos e objetos, viam-se paisagens, espaços relacionais de produção de sujeitos e objetos.

O MO_AND transfigurou minha pesquisa, trouxe para o uso muitos conceitos, interferiu diretamente na maneira como pensei e produzi a expressividade do que vivi no campo e da proposição que quis fazer com a tese de doutorado: uma clínica de território. Minha pesquisa tratava de enunciar a prática de cuidado de uma equipe de saúde que trabalhava com pessoas que viviam nas rua no centro da cidade do Rio de Janeiro. Para fazer isso, construímos espaços de conversa com os profissionais, que partiam de enunciados iniciais dos mesmos sobre suas práticas. Isso me pareceu como um espaço de jogo: havia uma posição inicial, colocada pelos trabalhadores, e a partir disso, nós pesquisadores íamos colocando nossas posições, até acharmos um jogo que produzia uma composição, que seria ao fim, a expressão da prática clínica naquele território que era onde a equipe se desenhava. Expressão que não seria uma representação da prática, mas sim uma criação a partir da enunciação da experiência vivida. Era uma invenção o que fazíamos ali.

Fomos entendendo que o modo de fazer o grupo de discussão, a pesquisa, era operacionalmente similar ao modo de cuidar. Na prática de cuidado realizada entre trabalhadores e seus usuários/pacientes tratava-se de viver junto, de criar um jogo, de compor algo. E o cuidado já não seria nem uma ação que somente restauraria um estado de saúde anterior; nem era feito por alguém; nem explicado por um porquê. O cuidado era ele mesmo um ato de criação, de composição a partir de certo modo de se relacionar com o território existencial onde os sujeitos que viviam nas ruas do Centro do Rio eram formados. A prática de cuidar ia se definindo a partir da construção mapas de o quê, como, onde/quando. Menos cair na armadilha de explicar um porque e um quem, na situação de vida da pessoa que morava na rua, e mais acessar os

${ }^{9}$ Dimensão da experiência subjetiva que materializa (corporifica) o espírito em seu movimento criativo; espaço das intensidades livres que resistem à tendência estratificadora-organizadora dos processos de subjetivação. $\mathrm{O}$ que diz respeito à subjetividade em sua dimensão corpórea, ali onde opera uma lógica da sensação, uma linguagem a-significante. Mais à frente desdobraremos esse termo. 
processos de constituição daqueles territórios de vida. Nessa estratégia territorial de cuidado, podia-se conjurar os efeitos nefastos que práticas de saúde com as zonas à margem da sociedade podem ganhar: normalização, adaptação, inclusão serializada. A prática de cuidado, como modo de compor com todo um território-paisagem se aproximava mais de uma prática de composição, onde aqueles que tinham mandato social de cuidado, passam a ser mais um elemento do tabuleiro. Não estando em posição exterior e superior - sobre, contra os territórios de vida dos usuários - mas em com-posição: no território, a partir do território, com o território, para o território. Tomar parte, habitar o território de vida dos usuários, essa era a direção que ganhava o cuidado. Era a partir de um certo agenciamento coletivo, territorial que o cuidado se dava. Ao modo da composição. O cuidado era efeito de um modo de operar, que chamamos de clínica, mas que opera de maneira similar ao jogo: que envolvia a criação, o corpo, um certo corpo atento que repara, um certo recorte espaço-tempo que seria uma zona de atenção, que seria a composição com aquilo que ali, naquele recorte territorial se apresentava: polícia, miséria, lixo, comida, bueiros, calçadas, tráfico, corpos em transe, corpos indiferentes... Enfim, todos os elementos que construíam a paisagem da rua: como a enfermeira usava os cobertores que estavam escondidos nos bueiros para fazer uma enfermaria na rua; a confiança que o cachorro do usuário precisava ter nos profissionais para que o tratamento fosse em frente. Era preciso compor com e a partir dos mais diversos elementos da rua, entender o efeito que aquilo gerava. A transformação daquelas experiências era territorial: o território mudava, os profissionais mudavam, os pacientes, os transeuntes, os outros atores que faziam parte da rua habitada. O cuidado já não era somente uma ação de um ente, mas um efeito de rede: cuidado era uma rede, um território de relação que se formava no próprio território de vida das pessoas que viviam naquelas ruas.

Estas são as corposições iniciais que oferecemos no espaço de jogo de nosso coletivo. Entramos em modo jogo com essas posições, com estes corpos. O jogo faz com que esses corpos se transformem entre si, com que cada corpo se corporifique em sua prática singular de maneira diferente. Mesmo falando por meio de primeiras pessoas do singular, o que almejamos aqui foi antes uma polifonia espiralada dos modos de enunciar essa coletivização de singularidades que compõem uma corporeidade comum: convocação do corpo para a sua transformação e abertura ao mundo, o corpo como nó de uma rede, como superfície de contato e de articulação das forças moleculares. Uma corporeidade comum que se produz e é produzida reciprocamente pelos enlaces que dão relevo ao afeto, performatividade e território, numa zona de fricção e de composição entre CTR e MO_AND, dança e clínica, práticas artísticas e de cuidado.

\section{3- Corposições: profanações entre afeto, performatividade e território}

Enunciamos! Encontramos um plano comum entre estes corpos e perspectivas. E é a partir dessa enunciação que pudemos explorar estas linhas de força que nos perpassam a todos, quais sejam afeto, performatividade e território. Nesta exploração precisamos assumir um modo de operar singular deste grupo: a profanação. Ao dessacralizar nossas ferramentas iniciais, nos apropriamos efetivamente delas, as fizemos nossas. Tomamos posição! Compusemos juntos nosso corpo em posição, em posições: Corposições.

A partir da enunciação atual do grupo, notamos que nossas linhas de força constituem - em suas possíveis relações - relevos do que entendemos como corporeidade.

Corporeidade: dimensão processual e situada; evidenciando o corpo em sua autoprodução (GIL, 2004), conectado à subjetividade pelas relações sensíveis, pelos afetos; o corpo em ato e atualização constante, sempre em vias de performatizar os seus estados de presença em um espaço temporalizado e heterogêneo capaz de territorializar sua existência. Ali onde o corpo está para além dos limites do organismo. Corporeidade é processual, mutável e contingente, é a abertura do corpo ao mundo. É uma dimensão corpórea entre o ver e o dizer, que implicam uma concomitância entre pensarsentir-dizer. Quando investimos nossa corporeidade nas relações, intensificamos o plano comum: os corpos são tecidos e tecem relações simultâneas de afetabilidade, comunicação e contágio com outros corpos.

Performatividade (AUSTIN, 1990): ato de inscrição e concretização da presença deste corpo afetivo e relacional no mundo. Performar é fazer agir em ato, realizar atividade; é o corpo em sua contínua atualidade, agindo no espaço e no tempo, lidando com o movimento constante do seu aparecimento e do seu apagamento. No ato performativo não só se cria o corpo que performa (em uma dinâmica de circularidade operacional). Mas também se cria o espaço, o meio. Se cria o território.

Território: plano de expressão (criação) de uma existência. Território (DELEUZE; GUATTARI, 1997; GUATTARI, 1992) não é sinônimo de espaço, mas é um espaço tornado expressivo, um espaço/tempo, sempre provisório, no qual emergem sujeitos e objetos. É pensar qualquer existente como sendo produzido em relação a uma alteridade, em um espaço de relação. É sempre em um território que se performa o corpo. O território é o territorializado (forma) e a desterritorialização (processo), o movimento que o anima, que o torna vivo. É ato de repetição estilizada. O território é um performar sem autor, sem agente-origem. Corpo e território são meios acessíveis à nossa configuração existencial para chegar ao comum. É sempre em um território que o comum aparece como evento fenomenológico, e é sempre por meio do corpo, como articulação paradoxal entre o olhar subjetivo e objetivo (ROLNIK, 1998).

Plano comum: onde a corporeidade está assentada, superfície de contato, articulação das forças. Espaço de interface do interior com o exterior. O plano comum é o plano das relações, o plano dos afetos. A construção de um plano comum de leitura sem apagamento das subjetividades torna-se um desafio constante da vida em comunidade. 
Afeto: é a materialidade, o meio condutor das relações, das trocas, das transformações entre os corpos. Ele é a qualidade de um território; ele é a matéria articulada em um corpo. É no plano afetivo da realidade que o performar age, e daí, por reverberação, age nas coisas e nas pessoas, nos sujeitos e objetos. Podemos dizer que nossa matéria prima de experimentação e investigação são os afetos, que é diferente do sentimento pessoal. $\mathrm{O}$ afeto diz respeito a um pré-pessoal, pressubjetivo, préorganísmico.

Profanação (AGAMBEN, 2007): inserção de um novo sentido naquilo que já existe e tem sua razão de ser no mundo, é mais que um simples jogo de sentidos, é uma estratégia de modificação das relações poder-saber e de diferenciação da partilha sensível entre os corpos. Profanar não é o fim, não é o objetivo do Corposições, mas sim resistir aos dispositivos de poder, de modo sempre singular, circunscrito e temporário.

Nossas experiências de composição e nossos exercícios de pensamento emergem numa tarefa de "pensação" (EUGENIO; FIADEIRO, 2013), qual seja, desestabilizar os sentidos instituídos em um território performatizado pela afetabilidade de um pensamento-corpo. Profanamos o MO AND e a CTR, veiculada e concomitante a essa primeira profanação, profanamos também cada uma de nossas práticas-trajetórias que trazemos para o espaço de jogo do coletivo.

Re-existimos a cada encontro. Cada um de nós ativa o próprio fazer através do fazer do outro, "colocando-se com" sendo este ato o aspecto crucial do que vem a ser com-posição no âmbito desta perspectiva. Partilhamos um esforço coletivo de habitar as questões uns dos outros, inibindo reflexos, retrocedendo na ação de saber como interpretação e fixação de significados. Este esforço pode ser análogo ao esforço do espectador ao se deparar com uma obra de arte contemporânea, do crítico de arte ao abordar ações artísticas ou de um psicanalista no processo de escuta e registro das dramaturgias múltiplas construídas por seu paciente. Tanto na arte, quanto na clínica, o exercício é o de alargar a relação com as formas e passar a se relacionar com elas como forças.

\section{Referências}

AGAMBEN, G. Profanações. São Paulo: Boitempo, 2007.

AUSTIN, J. L. Quando dizer é fazer. Porto Alegre: Artes Médicas, 1990.

BASBAUM, R. Amo os Artistas Etc. in: MOURA, R. (Org.). Políticas Institucionais, Práticas Curatoriais. Belo Horizonte: Museu de Arte da Pampulha, 2005. Disponível em: <https:// rbtxt.files.wordpress.com/2009/09/artista_etc.pdf > . Acesso em 28 ago 2017.

CASTRO, E. V. Os pronomes cosmológicos e o perspectivismo ameríndio. Mana, Rio de Janeiro, v. 2, n. 2, p. 115-144, out. 1996. Cross ${ }^{\text {Ref. }}$

CASTRO, E. V. Metafísicas canibales: líneas de antropología postestructural. Buenos Aires: Katz, 2010.

DELEUZE, G. Conversações. Rio de Janeiro: Editora 34, 1992.

DELEUZE, G. O que é um dispositivo? In: O mistério de Ariana. Lisboa: Vega, 1996. p. 83-96.
DELEUZE, G.; PARNET, C. Diálogos. São Paulo: Escuta, 1998.

DELEUZE, G.; GUATTARI, F. Mil platôs: capitalismo e esquizofrenia. Rio de Janeiro: Editora 34, 1997. v. 1.

EUGENIO, F. Sobre o And Lab. [201?]. Disponível em: $<$ https://www.and-lab.net/sobre>. Acesso em: 20 out. 2016.

EUGENIO, F.; FIADEIRO, J. O encontro é uma ferida. Excerto da conferência-performance Secalharidade de Fernanda Eugenio e João Fiadeiro. Lisboa: Culturgest, jun. 2012. Não paginado.

EUGENIO, F.; FIADEIRO, J. Jogo das perguntas: o modo operativo "AND" e o viver juntos sem ideias. Fractal, Rev. Psicol., Niterói, v. 25, n. 2, maio/ago. 2013. Cross ${ }^{\text {Ref. }}$

FIADEIRO, J. Composição em tempo real. Dossier de divulgação, 2016.

GUATTARI, F. Caosmose. Rio de Janeiro: Ed. 34, 1992.

GIL, J. Movimento Total: o corpo e a dança. São Paulo: Iluminuras, 2004.

JORGE, S. Movimento Autêntico: a arte de mover e ser movido. Instituto Junguiano do Rio de Janeiro. s.d. Disponível em: <http://www.jung-rj.com.br/artigos/movimento_autentico. pdf>. Acesso em: 2 set. 2016.

KALTENBRUNNER, T. Contact Improvisation: moving dancing - interaction. Oxford: Meyer und Meyer (UK), 1998.

KALTENBRUNNER, T. Contact Improvisation, bewegen, sich begegnen und miteinander tanzen. Aachen, Germany: Meyer \& Meyer, 2009.

MACEDO, G. Bright spots in Brazil. Contact Quaterly, New York State, v. 32, n. 2, summer/fall 2007.

MACERATA, I. Traços de uma clínica de território. 2015. Tese (Doutorado em Psicologia)-Universidade Federal Fluminense, Instituto de Ciências Humanas e Filosofia, Departamento de Psicologia, Niterói, 2015.

RANCIÈRE, J. A partilha do sensivel. São Paulo: Editora 34, 2005.

RANCIÈRE, J. O espectador emancipado. Lisboa: Orfeu Negro, 2010.

RESENDE, C. Coreografismos clínicos: contágio e outramento. In: SEMINÁRIO DA FACULDADE DE DANÇA ANGEL VIANNA, 6., 2012, Rio de Janeiro. Anais... Rio de Janeiro: Faculdade de Dança Angel Vianna. Disponível em: <http:// www.escolaangelvianna.com.br/seminario/anais/trabalho/ coreografismos-clinicos-contagio-e-outramento>. Acesso em: 12 jul. 2016.

ROLNIK, S. Subjetividade Antropofágica / Anthropophagic Subjectivity. In: HERKENHOFF, P.; PEDROSA, A. (Curadores). XXIV Bienal de São Paulo: Arte Contemporânea Brasileira: Um e/entre Outro/s. São Paulo: A Fundação, 1998. p. 128-147.

RUIZ, G. Graciela e Grupo Coringa: a dança contemporânea carioca dos anos 1970/80. Rio de Janeiro: Mauad, 2013.

Recebido em: 16 de novembro de 2016 Aceito em: 27 de abril de 2017 